\title{
Advanced Treatment of
}

\section{Intractable Childhood Epilepsy}

\section{Joo Hee Seo ${ }^{1}$, Kum Ok Choi ${ }^{1}$, Joon Soo Lee ${ }^{1}$, Heung Dong Kim ${ }^{1}$}

\author{
${ }^{1}$ Department of Pediatrics, Pediatric Epilepsy Clinic, Severance Children’s Hospital, \\ Yonsei University Health System, Korea
}

Key words: Intractable childhood epilepsy, New antiepileptic drugs, Ketogenic diet, Epilepsy Surgery

Published online: February 19, 2008

\begin{abstract}
Twenty to thirty percent of children with epilepsy continue to have seizures despite anti-epileptic drugs (AEDs) treatment and are defined as medically intractable epilepsy. Intractable epilepsy frequently has developmental impact, causing permanent neurodevelopmental deficits in children.

Recently developed neurodiagnostic studies and treatment modalities have substantially altered the management of patients with intractable epilepsy. The newly developed AEDs are frequently used for the treatment of patients unresponsive to conventional AEDs. Nonpharmacologic options for intractable epilepsy include dietary therapy such as ketogenic diet and modified

Atkins diet, epilepsy surgery, and neuromodulatory treatments such as vagus nerve stimulation. Ketogenic diet is an effective and safe treatment for epilepsy in children; increasing use has led to modification of protocol for higher efficacy and better tolerability. When epilepsy is intractable to medical treatment, epilepsy surgery including surgical resection of epileptogenic area, or palliative surgery can be considered. Vagal Nerve Stimulation is recommended for patients who are not candidates for resective surgery. These nonpharmcologic treatments could result in resumption of developmental progress in patients with childhood intractable epilepsy.
\end{abstract}


Active application of newly developed medical and surgical treatments could provide better outcome in seizure control and developmental progress in patients with intractable epilepsy.

\section{Introduction}

Epilepsy affects approximately 0.5 to $1 \%$ of general population through the life. Of those newly diagnosed as epilepsy, approximately $70 \%$ are children under the age of 16 years. Whereas the majority of patients with childhood-onset epilepsy attain remission, about 20 to 30 percents of children continue to have seizures despite active anti-epileptic drugs (AEDs) treatment and are defined as medically refractory epilepsy (1). Until recently, advanced treatments of medically intractable childhood epilepsy including newer AEDs, dietary therapy, epilepsy surgery, and neuromodulatory therapy have been developed and widely used. This review summarizes the advanced treatment modalities for children with medically intractable epilepsy.

\section{Newer antiepileptic drugs}

Traditionally, AED marketed before 1990 are defined as 'old' AED, while drugs that have been introduced after 1990 are considered 'newer' AED. In the past decade, more than 10 newer AEDs have been released, and most of these drugs have advantages in pharmacokinetics, tolerability, and drug interactions as compared with old AEDs such as phenobarbital, phenytoin (PHT), carbamazepine (CBZ), and valproic acid (VPA). Although the list of adverse ef- fects of the new AEDs is extensive, the majority of adverse effects is mild and can be either anticipated or readily reversed by dose reduction. As new AEDs with a variety of mechanisms of action become well known, it becomes more important to use these drugs as add-on therapy and first-line treatment in epilepsy. In this review we discuss the anticonvulsant mechanisms and clinical applications of the new drugs that are widely used in intractable childhood epilepsy.

\section{Vigabatrin}

Vigabatrin (VGB) is a specific, enzymeactivated irreversible inhibitor of GABA transaminase, the enzyme involved in GABA metabolism. The drug has been shown to be effective as add-on therapy in children with partial seizures and West syndrome, especially caused by tuberous sclerosis complex $(2,3,4)$. In 1996 the first case of visual field defect, a serious irreversible loss of peripheral vision, was reported in association with VGB, followed by increased recognition of the frequency of this unique adverse effect in over $60 \%$ of patients (5). As the defects cannot be tested in children, VGB, initially marketed for treating partial epilepsy, was virtually abandoned except for special situations. The recommended starting dose is $40 \mathrm{mg} / \mathrm{kg}$ per day, which can be increased to 50-100 $\mathrm{mg} / \mathrm{kg}$ per day as required. In West syndrome, dosages of more than $100 \mathrm{mg} / \mathrm{kg}$ per day have been used (4). 


\section{Zonisamide}

Zonisamide (ZNS) was developed in $\mathrm{Ja}^{-}$ pan and has been widely used in Japan and South Korea (6). It acts on voltage-sensitive sodium channels and voltage-dependent $\mathrm{T}^{-}$ type calcium channels, without affecting $\mathrm{L}^{-}$ type calcium currents (7). Approved for the treatment of partial epilepsy, the drug has a broad spectrum of activity for both partial and generalized epilepsies, especially for myoclonic epilepsy (8). Treatment is started at $1.5 \mathrm{mg} / \mathrm{kg}$ per day, and gradually increased to a maximum of 10 to $15 \mathrm{mg} / \mathrm{kg}$ per day.

\section{Gabapentin}

Although gabapentin (GBP) was designed as a GABA agonist, the mode of action of this anticonvulsant, a structural analogue of GABA, is still uncertain. Its mechanism of action is thought to utilize the L-system of long chain amino acid transport system, transporting bulky hydrophobic acids through membranes, and additionally to have sodium channel effects (9). It is effective for monotherapy in newly diagnosed epilepsy. It is also effective in reducing seizure frequency as adjunctive therapy in patients with refractory partial seizures. $\mathrm{Al}$ though the advantage of GBP is its least adverse cognitive effects than other AEDs, reported side effects in some children include somnolence, fatigue, dizziness, and defiance (10).

\section{Lamotrigine}

Lamotrigine (LTG) was introduced in 1994 for the treatment of partial epilepsy, later extended to generalized epilepsy (11). Its mechanism of action is inhibition of voltage-sensitive sodium currents through interaction with slow inactivated sodium channels (12). It has a favorable pharmacokinetic profile, although $55 \%$ is bound to protein, and subject to major interaction with cytochrome p450 enzyme inducers, especially with VPA, which significantly inhibits its metabolism. It is effective both in partial and generalized seizures in children (13). LTG occasionally exacerbates the myoclonus in severe myoclonic epilepsy in infancy (14), which is another limiting factor of its use in this condition compared to VPA. Adverse effects reported were serious rashes and immunological disturbances, preventable by slow titration, especially in the presence of VPA. When LTG is given to a child who is already receiving VPA, a starting dose of 0.1 to $0.2 \mathrm{mg} / \mathrm{kg}$ per day is recommended, with slow increment to a maintenance dose of 1 - $5 \mathrm{mg} / \mathrm{kg}$ per day. When LTG is used as monotherapy, optimal doses range from 5 to $15 \mathrm{mg} / \mathrm{kg}$ per day, with a starting dose of approximately 1 to 2 $\mathrm{mg} / \mathrm{kg}$ per day.

\section{Topiramate}

Topiramate (TPM) is reported to have mechanisms of action including activity against ligand-gated $\mathrm{Na}^{+}$channels linked to AMPA subtype of glutamate receptors and, to a limited extent, blockade of voltagedependent $\mathrm{Na}^{+}$channels as well as enhancement of GABA-mediated $\mathrm{Cl}^{-}$currents (15). It is approved for treatment of partial seizures, and also for treating generalized 
epilepsy as a second-line drug (16). It has a favorable pharmacokinetic profile, and few interactions. TPM is associated with weight loss and paresthesias (17). The major side effect of the drug is its adverse action on cognitive function (18). Titration appears to be beneficial to decrease the incidence of cognitive deficits. Treatment is started at 0.5 to $1.0 \mathrm{mg} / \mathrm{kg}$ per day, and gradually increased to a maximum of 5 to $9 \mathrm{mg} / \mathrm{kg}$ per day. For West syndrome, higher dose upto $20 \mathrm{mg} / \mathrm{kg}$ per day can be tried.

\section{Oxcarbazepine}

Oxcarbazepine (OXC), a saturated analogue of CBZ that is devoid of the ability to be transformed to the 10,11-epoxide, has a pharmacologic spectrum and potency similar to that of CBZ, but a lower incidence of adverse effects such as rash and hypersensitivity reactions (19). OXC has a higher incidence of laboratory abnormalities, especially hyponatraemia, but this finding infrequently leads to complications (20). For partial seizures, it has a comparable efficacy as VPA, PHT, and CBZ, both in adults and children. Optimal dosage for children is $30 \mathrm{mg} / \mathrm{kg}$ per day, but can be increased to $60 \mathrm{mg} / \mathrm{kg}$ per day.

\section{Levetiracetam}

Levetiracetam (LEV) is an AED with linear pharmacokinetics, minimal metabolism, an incompletely described mechanism of action, and a unique preclinical profile. The mechanism of action seems to inhibit $\mathrm{N}$-type high-voltage-activated $\mathrm{Ca}^{2+}$ currents partially and reduces the neurotrans- mitter release from presynaptic vesicles (21). LEV has demonstrated efficacy and a favorable tolerability as an adjunctive therapy in adults and children with medically intractable epilepsy $(22,23)$. LEV also appears to have a broad spectrum. It was reported to be effective in generalized spike wave epilepsy (24), myoclonic epilepsy (25), and childhood syndromes such as rolandic epilepsy (26). There are no major side effects, but irritability and behavior changes are noted in some children. The overall tolerability of LEV is generally considered to be high. Dose range of LEV monotherapy is 15 to $60 \mathrm{mg} / \mathrm{kg}$ per day for children $(23,27)$.

Since 1990's, more than 10 newer AEDs have been developed and become available (16). As a consequence, choosing which drug to treat a patient with intractable childhood epilepsy has become more important. The selection of AEDs should be based on the best available data on the efficacy for the type of seizure or specific epilepsy syndrome, a consideration of the toxicities associated with the medication, with an appreciation of the comorbidities that may exist in children with epilepsy and paying attention to the adverse effect on cognition and behavior.

\section{Ketogenic diet}

The ketogenic diet (KD) is high fat, adequate protein and low carbohydrate diet, and has been shown to be an effective alternative treatment for children with medically intractable epilepsy (28). Historically, it was originally developed in the 1920s, but was not used until 1994 
when its highly effective anti-epileptic potential was introduced to public in some intractable pediatric cases (28). Currently $\mathrm{KD}$ is thought to be more effective than most of the newer AEDs (29). In general, at least half of all patients treated with the $\mathrm{KD}$ will show a $50 \%$ or greater reduction of seizure frequency $(28,30-33)$. Any seizure type may respond to the diet; some generalized seizure types including myoclonic, atonic, generalized tonic-clonic, and even infantile spasms may respond preferentially. The KD works in all ages, from infancy through adulthood, although it may be most effective in the toddler and school-aged child (34). A Korean multicentric study of KD efficacy at 6 and 12 months after the diet in 199 children with intractable epilepsy of different types revealed that more than $50 \%$ of patients remained on the diet; $58 \%$ and $41 \%$, respectively showed a reduction of seizure frequency of $>50 \%$, including $33 \%$ and $25 \%$ who became seizure free $(32,35)$. Although the conventional Asian diet contains substantially less fat than traditional Western diets, the $\mathrm{KD}$ is a safe and effective alternative therapy for intractable childhood epilepsy in Korea (32, 36, 37).

The mechanism of $\mathrm{KD}$ on seizures is still unknown. It is suggested that $\mathrm{KD}$ affects intermediary metabolism that influences the dynamics of the major inhibitory and excitatory neurotransmitter systems in brain $(32,38)$. During consumption of the $\mathrm{KD}$, alterations in brain energy metabolism occur, with ketone bodies replacing glucose as fuel (39). Although the exact mechanism of its anti-epileptic efficacy is still unclear, the ketone body could play a role in seizure protection.

The KD is most commonly initiated during a 5- to 7-day hospitalization. The diet involves restricting protein and carbohydrate intake and supplying about 80 to $90 \%$ of calorie intake through fats. The classical Johns-Hopkins protocol has been revised by elimination of the initial fasting period, starting with one-third of the total calories on day 1 , two-thirds of total calories on day 2 , and the full calorie diet on day 3 , as the patient tolerates (37). Hospitalization allows close monitoring of potential side effects during the initial $\mathrm{KD}$ administration as well as adequate education to family for its home maintenance $(28,31,40)$. A Korean study of KD complications in 129 chil- $^{-}$ dren revealed that the most common earlyonset complication was dehydration, especially in patients who started the KD with initial fasting (41). Other early-onset complications are gastrointestinal disturbance, transient alteration of lipid profiles, various infectious diseases, symptomatic hypoglycemia, electrolyte imbalance and persistent metabolic acidosis. Late-onset complications include osteopenia, renal stones, cardiomyopathy, secondary hypocarnitinemia, and iron-deficiency anemia. Most complications of the $\mathrm{KD}$ are transient and can be easily managed with various conservative treatments (41).

\section{Epilepsy Surgery}

When epilepsy is intractable to medical treatment, surgical resection of the tissue responsible for the epilepsy should be con- 
sidered (42). The evaluations to identify an epileptogenic area include a study of the seizure semiology, neurological examination, video-electroencephalography (EEG) monitoring, high resolution magnetic resonance imaging (MRI) and neuropsychological evaluation (43). Advanced neuroimaging including positron emission tomography (PET), single photon emission computerized tomography (SPECT) and magnetoencephalography (MEG) may be helpful to determine the epileptogenic area (44). Invasive intracranial monitoring can be performed to confirm the exact location and margin of the actual epileptogenic area. Invasive study is also important to differentiate the eloquent cortex from epileptogenic region in addition to functional mapping (45). The types of procedures used in the resective surgical treatment of epilepsy in children consist of focal resection of temporal lobectomy, extratemporal cortisectomy or lobectomy, and hemisphere(o)ctomy. Corpus callosotomy is performed as a palliative procedure because it is only helpful for drop attacks and not for other types of seizures to interrupt the spread of epileptic discharges from one hemisphere to the other (46). Multiple subpial transaction can prevent seizures from spreading but leave the function of the area intact (47). Therefore, it is often used where there is involvement of eloquent cortex. The seizure outcome of epilepsy surgery in appropriately selected cases is much better than those treated with AEDs. In children who underwent temporal lobectomy, a favorable outcome (Engel Class 1 or 2) has been reported in more than $75 \%$ (48). For children who underwent extratemporal focal cortical resection, the percentage achieving a favorable outcome (Engel Class 1 and 2) is suggested to be more than $50 \%$, which is less than temporal lobectomy $(49,50)$. For the treatment of intractable childhood epilepsy, it is important to diagnose intractability early and identify the surgically remediable epilepsy syndromes prior to the cessation of neuronal plasticity (51).

\section{VNS (vagal nerve stimulation)}

Electrical stimulation of the vagus nerve (VNS) is a neuromodulatory treatment that was developed in the late 1980s and is currently conducted in specialized epilepsy centers worldwide (52). The mechanism of action of VNS is poorly understood. The left vagus nerve consists of afferent fibers, and these fibers terminate in the nucleus of the solitary tract. It is suggested that intermittent stimulation of vagus nerve using a neuron cybernetic prosthesis can activate cortical and subcortical structures, which are projected from the nucleus of solitary tract. Even though acute changes in neurotransmitter metabolites such as norepinephrine have been demonstrated in the CSF, the gradual increase in efficacy of chronic stimulation suggests some plastic changes in circuitry.

Clinical studies over the past two years have reported efficacy of VNS in specific patient groups, including those with bitemporal epilepsy, Lennox-Gastaut syndrome, persistent seizures after epilepsy surgery, and patients who use the supplied magnet to abort or attenuate 
seizures (52, 53). Other studies have confirmed long-term seizure control and emphasized the potential benefit of improving the quality of life and cognitive function in a patient's course of epilepsy (54). Although clinical efficacy has been demonstrated in children in Korea, its use is limited due to the high cost (55).

\section{Other advanced therapy}

There are other experimental trials for intractable epilepsy, including electrical cortical stimulation, direct delivery of AEDs into epileptogenic cortex, gene therapy and cell therapy. Further studies demonstrating the safety and efficacy of these advanced therapies for intractable epilepsy should be performed.

\section{Conclusion}

Active application of newly developed medical and surgical treatments could provide better outcome in seizure remission and developmental progress in patients with intractable epilepsy. Further research and development for the treatment of intractable childhood epilepsy may provide some hope to families struggling with intractable epilepsy.

\section{References}

[1] Kwan P, Brodie MJ. Refractory epilepsy: mechanisms and solutions. Expert Rev Neurother. 2006: 6: 397-406.

[2] Schousboe A, Waagepetersen HS. Glial modulation of GABAergic and glutamat ergic neurotransmission. Curr Top Med Chem. 2006: 6: 929-934.
[3] Wheless JW, Ramsay RE, Collins SD. Vigabatrin. Neurotherapeutics. 2007: 4: 163-172.

[4] Curatolo P, Verdecchia M, Bombardieri R. Vigabatrin for tuberous sclerosis complex. Brain Dev. 2001: 23: 649-653.

[5] Verrotti A, Manco R, Matricardi S, Franzoni E, Chiarelli F. Antiepileptic drugs and visual function. Pediatr Neurol. 2007: 36: 353-360.

[6] Arzimanoglou A, Rahbani A. Zonisamide for the treatment of epilepsy. Expert Rev Neurother. 2006: 6: 1283-1292.

[7] Baulac M. Introduction to zonisamide. Epilepsy Res. 2006: 68 Suppl 2: S3-9.

[8] Leppik IE. Practical prescribing and longterm efficacy and safety of zonisamide. Epilepsy Res. 2006: 68 Suppl 2: S17-24.

[9] Hamandi K, Sander JW. Pregabalin: a new antiepileptic drug for refractory epilepsy. Seizure. 2006: 15: 73-78.

[10] McLean MJ, Gidal BE. Gabapentin dosing in the treatment of epilepsy. Clin Ther. 2003: 25: 1382-1406.

[11] Choi H, Morrell MJ. Review of lamotrigine and its clinical applications in epilepsy. Expert Opin Pharmacother. 2003: 4: 243-251.

[12] Culy CR, Goa KL. Lamotrigine. A review of its use in childhood epilepsy. Paediatr Drugs. 2000: 2: 299-330.

[13] Messenheimer J. Efficacy and safety of lamotrigine in pediatric patients. J Child Neurol. 2002: 17 Suppl 2: 2S34-32S42.

[14] Guerrini R, Dravet C, Genton P, Belmonte A, Kaminska A, Dulac O. Lamotrigine and seizure aggravation in severe myoclonic epilepsy. Epilepsia. 1998: 39: 508-512.

[15] Lyseng-Williamson KA, Yang LP. Topi- 
ramate: a review of its use in the treatment of epilepsy. Drugs. 2007: 67: 22312256.

[16] Connock M, Frew E, Evans BW, Bryan S, Cummins C, Fry-Smith A, Li Wan Po A, Sandercock J. The clinical effectiveness and cost-effectiveness of newer drugs for children with epilepsy. A systematic review. Health Technol Assess. 2006: 10: iii, ix-118.

[17] Franzoni E, Verrotti A, Sarajlija J, Garone C, Matricardi S, Salerno GG, Monti M, Chiarelli F. Topiramate: effects on serum lipids and lipoproteins levels in children. Eur J Neurol. 2007.

[18] Coppola G, Verrotti A, Resicato G, Ferrarelli S, Auricchio G, Operto FF, Pascotto A. Topiramate in children and adolescents with epilepsy and mental retardation: A prospective study on behavior and cognitive effects. Epilepsy Behav. Published online: 23-Oct-2007; doi:10.1016/j.yebeh. 2007.09.001

[19] Horga de la Parte JF, Horga A. [Oxcarbazepine in the treatment of epilepsy. A review and update]. Rev Neurol. 2006: 42: 95-113.

[20] Asconape JJ. Some common issues in the use of antiepileptic drugs. Semin Neurol. 2002: 22: 27-39.

[21] Lukyanetz EA, Shkryl VM, Kostyuk PG. Selective blockade of $\mathrm{N}$-type calcium channels by levetiracetam. Epilepsia. 2002: 43: 9-18.

[22] Ben-Menachem E, Falter U. Efficacy and tolerability of levetiracetam $3000 \mathrm{mg} / \mathrm{d}$ in patients with refractory partial seizures: a multicenter, double-blind, responderselected study evaluating monotherapy. European Levetiracetam Study Group.
Epilepsia. 2000: 41: 1276 -1283.

[23] Glauser TA, Ayala R, Elterman RD, Mitchell WG, Van Orman CB, Gauer LJ, $\mathrm{Lu}$ Z. Double-blind placebo-controlled trial of adjunctive levetiracetam in pediatric partial seizures. Neurology. 2006: 66: 1654-1660.

[24] Gallagher MJ, Eisenman LN, Brown KM, Erbayat-Altay E, Hecimovic H, Fessler AJ, Attarian HP, Gilliam FG. Levetiracetam reduces spike-wave density and duration during continuous EEG monitoring in patients with idiopathic generalized epilepsy. Epilepsia. 2004: 45: 9091.

[25] Genton P, Gelisse P. Suppression of posthypoxic and post-encephalitic myoclonus with levetiracetam. Neurology. 2001: 57: 1144-1145.

[26] Bello-Espinosa LE, Roberts SL. Levetiracetam for benign epilepsy of childhood with centrotemporal spikes-three cases. Seizure. 2003: 12: 157-159.

[27] Perry MS, Benatar M. Efficacy and tolerability of levetiracetam in children younger than 4 years: a retrospective review. Epilepsia. 2007: 48: 1123-1127.

[28] Groesbeck DK, Bluml RM, Kossoff EH. Long-term use of the ketogenic diet in the treatment of epilepsy. Dev Med Child Neurol. 2006: 48: 978-981.

[29] Huffman J, Kossoff EH. State of the ketogenic $\operatorname{diet}(\mathrm{s})$ in epilepsy. Curr Neurol Neurosci Rep. 2006: 6: 332-340.

[30] Coppola G, Veggiotti P, Cusmai R, Bertoli S, Cardinali S, Dionisi-Vici C, Elia M, Lispi ML, Sarnelli C, Tagliabue A, Toraldo C, Pascotto A. The ketogenic diet in children, adolescents and young adults with refractory epilepsy: an Ital- 
ian multicentric experience. Epilepsy Res. 2002: 48: 221-227.

[31] Freitas A, da Paz JA, Casella EB, Marques-Dias MJ. Ketogenic diet for the treatment of refractory epilepsy: a 10 year experience in children. Arq Neuropsiquiatr. 2007: 65: 381-384.

[32] Kang HC, Kim YJ, Kim DW, Kim HD. Efficacy and safety of the ketogenic diet for intractable childhood epilepsy: Korean multicentric experience. Epilepsia. 2005: 46: 272-279.

[33] Kossoff EH, McGrogan JR. Worldwide use of the ketogenic diet. Epilepsia. 2005: 46: 280-289.

[34] Rubenstein JE, Kossoff EH, Pyzik PL, Vining EP, McGrogan JR, Freeman JM. Experience in the use of the ketogenic diet as early therapy. J Child Neurol. 2005: 20: 31-34.

[35] Kang HC, Kim HD. Diet therapy in refractory pediatric epilepsy: increased efficacy and tolerability. Epileptic Disord. 2006: 8: 309-316.

[36] Eun SH, Kang HC, Kim DW, Kim HD. Ketogenic diet for treatment of infantile spasms. Brain Dev. 2006: 28: 566-571.

[37] Kim DW, Kang HC, Park JC, Kim HD. Benefits of the nonfasting ketogenic diet compared with the initial fasting ketogenic diet. Pediatrics. 2004: 114: 16271630.

[38] Liao JX, Lu XG, Cao DZ. [Ketogenic diet for treatment of epilepsy]. Zhongguo Dang Dai Er Ke Za Zhi. 2007: 9: 517-520.

[39] Haymond MW, Howard C, Ben-Galim E, DeVivo DC. Effects of ketosis on glucose flux in children and adults. Am J Physiol. 1983: 245: E373-378.

[40] Seo JH, Lee YM, Lee JS, Kang HC, Kim
HD. Efficacy and tolerability of the ketogenic diet according to lipid:nonlipid ratios--comparison of 3:1 with 4:1 diet. Epilepsia. 2007: 48: 801-805.

[41] Kang HC, Chung DE, Kim DW, Kim HD. Early- and late-onset complications of the ketogenic diet for intractable epilepsy. Epilepsia. 2004: 45: 1116-1123.

[42] Arango MF, Steven DA, Herrick IA. Neurosurgery for the treatment of epilepsy. Curr Opin Anaesthesiol. 2004: 17: 383-387.

[43] Olson DM. Evaluation of children for epilepsy surgery. Pediatr Neurosurg. 2001: 34: 159-165.

[44] Kurian M, Spinelli L, Delavelle J, Willi JP, Velazquez M, Chaves V, Habre W, Meagher-Villemure K, Roulet E, Villeneuve JG, Seeck M. Multimodality imaging for focus localization in pediatric pharmacoresistant epilepsy. Epileptic Disord. 2007: 9: 20-31.

[45] Liegeois F, Cross JH, Gadian DG, Connelly A. Role of fMRI in the decisionmaking process: epilepsy surgery for children. J Magn Reson Imaging. 2006: 23: 933-940.

[46] Clarke DF, Wheless JW, Chacon MM, Breier J, Koenig MK, McManis M, Castillo E, Baumgartner JE. Corpus callosotomy: a palliative therapeutic technique may help identify resectable epileptogenic foci. Seizure. 2007: 16: 545-553.

[47] Chuang MF, Harnod T, Wang PJ, Chen YH, Hsin YL. Effect of multiple subpial transection on patients with uncontrolled atypical infantile spasms. Epilepsia. 2006: 47: 659-660.

[48] Cai LX, Li YJ, Zhang GJ, Yu T, Du W. [Surgical treatment of lesional temporal 
lobe epilepsy]. Zhonghua Wai Ke Za Zhi. 2007: 45: 103-105.

[49] Delalande O, Fohlen M, Bulteau C, Jalin C. [Surgery for intractable focal epilepsy in children]. Rev Neurol (Paris). 2004: 160 Spec No 1: 5S195-202.

[50] Marsh EB, Freeman JM, Kossoff EH, Vining EP, Rubenstein JE, Pyzik PL, Hemingway $\mathrm{C}$. The outcome of children with intractable seizures: a $3^{-}$to 6-year follow-up of 67 children who remained on the ketogenic diet less than one year. Epilepsia. 2006: 47: 425-430.

[51] Hirsch E, Arzimanoglou A. [Children with drug-resistant partial epilepsy: criteria for the identification of surgical candidates]. Rev Neurol (Paris). 2004: 160 Spec No 1: 5S210-219.

[52] DeGiorgio CM, Schachter SC, Handforth A, Salinsky M, Thompson J, Uthman B, Reed R, Collins S, Tecoma E, Morris GL, Vaughn B, Naritoku DK, Henry T, Labar D, Gilmartin R, Labiner D, Osorio I, Ristanovic R, Jones J, Murphy J, Ney G, Wheless J, Lewis P, Heck C. Prospective long-term study of vagus nerve stimulation for the treatment of refractory seizures. Epilepsia. 2000: 41: 1195-1200.

[53] Murphy JV, Torkelson R, Dowler I, Simon S, Hudson S. Vagal nerve stimulation in refractory epilepsy: the first 100 patients receiving vagal nerve stimulation at a pediatric epilepsy center. Arch Pediatr Adolesc Med. 2003: 157: 560-564.

[54] You SJ, Kang HC, Kim HD, Ko TS, Kim DS, Hwang YS, Lee JK, Park SK. Vagus nerve stimulation in intractable childhood epilepsy: a Korean multicenter experience. J Korean Med Sci. 2007: 22:
442-445.

[55] Kang HC, Hwang YS, Kim DS, Kim HD. Vagus nerve stimulation in pediatric intractable epilepsy: a Korean bicentric study. Acta Neurochir Suppl. 2006: 99: 93-96. 